\title{
Omuz çevresi tuzak nöropatiler: supraskapular sinir sıkışması ve kuadrangüler aralık sendromu
}

\author{
Nerve entrapment around shoulder: suprascapular nerve entrapment and \\ quadriangular space syndrome \\ Gazi Huri, Egemen Turhan, Mahmut Nedim Doral \\ Hacettepe Üniversitesi Tıp Fakültesi, Ortopedi ve Travmatoloji Anabilim Dalı, Sıhhiye, Ankara
}

Omuz çevresi sinir sıkışmaları birçok hastada çeşitli nedenlere bağlı olarak ortaya çıkabilmektedir. Bunların içerisinde supraskapular sinir ve aksiller sinir en sık etkilenenleridir. Derlememizde omuz çevresi sinir sıkışmalarının tartışılması planlanmıştır.

Anahtar sözcükler: omuz; supraskapular sinir; sıkışma sendromu
Nerve entrapments around shoulder occur in different patients due to a variety of conditions and with many potential causes. Suprascapular nerve and axillary nerve are the most frequent effected nerves around shoulder. In this review, nerve entrapment syndormes around shoulder will be discussed.

Key words: shoulder; suprascapular nerve; entrapment syndrome
O muz eklemi, insan vücudunda en geniş hareket yeteneğine sahip olması ve elin fonksiyonel olarak kullanılmasına izin vermesi açısından büyük önem taşır. Omuz ağrıları, sıkça görülen, omuz hareketlerini ve fonksiyonunu kısıtlayan durumlardır. Omuz ağrıları birçok nedene bağlı ortaya çıkabilirken, daha ender görülse de, omuz çevresi tuzak nöropatiler de akılda tutulmalıdır.

Tuzak nöropatiler, tek sinirin özellikle fibro-osseoöz bir tünelden geçerken uğradığı mekanik dinamik kompresyona sekonder gelişmektedir. Omuz etrafında aksiller sinir ve brakiyal pleksus, en sık etkilenerek, klinikte ağrı ve hissizlik oluşturur. Omuz çevresi güçsüzlüğe neden olan sinir sıkışmaları; aksiller, brakiyal pleksus, uzun torasik, spinal aksesuvar ve supraskapular sinir patolojileridir. ${ }^{[1]}$ Brakiyal pleksus retropektoralis minör, kostoklavikular, interskalen boşluklarda sıkışmaktadır. Bu derlememizde, omuz çevresi görülen supraskapular sinir sıkışma sendromu ve kuadrangüler aralık sendromu (KAS) tartışılacaktır.

\section{SUPRASKAPULAR SINIR SIKIŞMA SENDROMU}

\section{Anatomi}

Supraskapular sinir, C5-C6 sinir köklerinden çıkarak brakiyal pleksusun üst trunkusundan ayrilan, motor ve duysal lifleri bulunan bir periferik sinirdir. Posterior servikal üçgenden geçtikten sonra supraskapular çentiğe ulaşır. ${ }^{[2]}$ Supraskapular çentikten, transvers skapular bağın altından skapula arkasına geçip, skapulanın supraspinöz fossasında ilerler ve supraspinatus ile infraspinatus kaslarını innerve eder.

\section{Patofizyoloji}

Bu sinirin hasarı ilk, olarak 1959 yılında Kopell ve Thompson tarafından tanımlanmıştır. ${ }^{[3]}$ Sinirin, omuzun abduksiyon, horizontal adduksiyon, ve aşırı traksiyonu ile, başta supraskapular oluk olmak üzere, anatomik yolu boyunca sıkışabileceğini göstermişler$\operatorname{dir}^{[4]}$

Supraskapular nöropatinin etiyolojisinde, travma, nöritis ve yavaş progresyon gösteren kompresif lezyonlar bulunur. ${ }^{[4]}$ Supraskapular nöropati ile ilişlkili omuz ağrıları, sporla uğraşan kişilerde travmaya sekonder olarak görülmekte ve özellikle baş üstü aktivite gösteren voleybol oyuncuları, beyzbol atıcıları, basketbol oyuncuları ve dansçılarda sinirin tekrarlayan gerilmesi, etiyolojik faktör olarak gösterilmektedir. ${ }^{[5]}$ Supraskapular nöropati; brakiyal nörit, subakromiyal sıkışma, glenohumeral instabilite, rotator manşet lezyonları, servikal radikülopatiler, neoplazmlar, tendi-

- Illetişim adresi: Doç. Dr. Gazi Huri, Hacettepe Üniversitesi Tıp Fakültesi, Ortopedi ve Travmatoloji Anabilim Dalı, Sıhhiye, Ankara Tel: 0532 - 4869155 e-posta: gazihuri@hacettepe.edu.tr

- Geliș tarihi: 13 Ekim $2015 \quad$ Kabul tarihi: 13 Ekim 2015 
nitler, adesiv kapsülitler, travma ve dejeneratif hastalıklar ile karışabilir ya da bunlarla birlikte görülebilir. ${ }^{[6]}$

Supraskapular oluk, anatomik yapısı itibarı ile, sinirin dış etkenlere en zayıf olduğu nokta olup, sinir hasarı sıklıkla bu bölgede ortaya çıkar. ${ }^{[3]}$

Supraskapular sinir tuzağı skapular çentik etrafında oluyorsa, hem supraspinatus hem de infraspinatus kasları; spinoglenoid çentik etrafında oluyorsa, sadece infraspinatus kası etkilenir. ${ }^{[7]}$ Supraskapular sinir sıkışması; skapula kırığı, omuz dislokasyonu, kitlelere bağı omuz hareketi esnasında supraskapular bağ tarafından kompresyonu sonucu oluşur. Kitle, çoğunlukla gangliyon olur ve spinoglenoid çentikte daha fazla görülür. Kapsulolabral yaralanma sonucu gangliyon, en sık izlenen senaryodur. ${ }^{[7]}$ Gangliyon, infraspinatus kas denervasyonuna yol açar; supraskapular bağ kompresyonu söz konusu ise, o zaman da hem infra hem de supraspinatus kası etkilenir. Skapular çentikte kompresyona yol açacak bir neden yokken, hem supraspinatus hem de infraspinatus kasında etkilenme varsa, ayırıcı tanıda Parsonage-Turner sendromuna sekonder nörit düşünülmelidir. ${ }^{[8]}$

\section{Klinik}

Supraskapular nöropati, sıklıkla omuz lateral ve posteriorunda yerleşen, künt ve iyi lokalize edilemeyen bir ağrı ile karşımıza çıkar. Etkilenen tarafta özellikle omuz dış rotasyonu ve abduksiyonu zayıflamış olup, sıklıkla servikal disk patolojileri ile karışır. Sıkışma supraskapular çentikte ise, ağrı daha belirgin ve klinik daha gürültülüdür. Ağrı, boyuna ve göğüs kafesi ön duvarına yayılım gösterebilir. Öyküsünde travma ve tekrarlayan mikrotravmalar olabilir. Travmatik olgularda, kol gergin iken üzerine düşme öyküsü sıktır. Baş üstü aktiviteler ile tekrarlayıcı mikrotravmaların görüldüğü, voleybol, basketbol, tenis, ağırlık kaldırma, yüzme gibi aktivitelerin varlığı iyice sorgulanmalıdır. ${ }^{[9-11]}$

Fizik muayene, genellikle non-spesifiktir. Hasta, sıklıkla omuz bölgesi posteriorunda ağrı şikayeti ile doktora başvurur. Sıklıkla, supraskapular çentik bölgesinde hassasiyet mevcuttur. Kronik olgularda supraspinatus ve infraspinatus kaslarında direkt bakı ile atrofi görülmesi, bunun yanı sıra deltoidin normal olması, tanıyı destekleyen önemli bir bulgudur. Dış rotasyonda ve bazı olgularda, abduksiyonda zayıflık dikkat çekicidir. Ayrıca, "cross-body adduction" testi de, özellikle iç rotasyonda ağrılıdır. ${ }^{[9]}$

Tanıda, fizik muayenenin yanı sıra elektrodiyagnostik incelemeler ve radyolojik görüntülemeler kullanılır. Ayrıcı tanıda, servikal disk hastalıkları akılda tutulmalıdır. İzole boyun ağrısı ve radiküler ağrı, daha çok disk patolojilerini düşündürmektedir. Supraskapular çentiğe uygulanan sinir bloğu işlemi, tanıda değerlidir. ${ }^{[12]}$

Radyolojik değerlendirme, özellikle sinirin basıya uğradığı yerin tespitinde önemlidir. Eşlik eden kırıkların tayininde ise direkt grafiler önemlidir. Supraskapular çentiğin görüntülenmesi için Stryker notch grafisi, çentikteki kemiksel anomalilerin tayininde de bilgisayarlı tomografi (BT) önemlidir. Manyetik rezonans (MR) incelemesi, supraskapular sinir sıkışmalarında uygulanması önerilen en ideal görüntüleme yöntemidir. Bu yöntem, sinirin görüntülenmesinin yanı sıra, etkilenen yumuşak doku ve kas kitlesi hakkında da bilgi sağlar. Sıklıkla, gangliyon kisti gibi boşluk dolduran lezyonlar sinir sıkışmasına neden olabilmektedir. MR de, bunların tanısında en iyi araçtır. Gangliyon kisti, tipik olarak homojen görüntüde, T1 ağırlıklı kesitlerde hipointens, T2 ağırlıklı kesitlerde ise hiperintens olarak tespit edilir. ${ }^{[13]}$

\section{Tedavi}

Supraskapular sinir sıkışması tedavisine karar verirken, sistematik bir yol izlenmelidir (Şekil 1). Konservatif tedavi seçeneğinden, cerrahi, açık veya artroskopik tedavi seçeneğine kadar, geniş bir tedavi yelpazesi bulunmaktadır. ${ }^{[14]}$

\section{KUADRANGÜLER ARALIK SENDROMU (KAS)}

ilk olarak 1980 yılında, Cahill ve arkadaşları tarafından tanımlanmıştır. ${ }^{[15]}$

Kuadrangüler aralık, aksiller sinir ve posterior sirkumfleks humeral arterin geçtiği önemli bir boşluktur. Bu boşluk içerisinde bası altında kalan yapı, eğer aksiller sinir ise kliniğin adı nörojenik kuadrangüler aralık sendromu (nKAS), posterior sirkumfleks humeral arter ise vasküler kuadrangüler aralık sendromu (vKAS) olarak adlandırılır. ${ }^{[16]}$ nKAS, göreceli olarak 1,5:1 oranında, vKAS'tan daha sıktır. Özellikle, 20-40 yaş aralığındaki erkekler etkilenir ve bu hastalar, subakromiyal sıkışma sendromu ile karışırlar. Baş üstü aktivite içeren spor dalları ile uğraşan sporcularda daha fazla görülür.

\section{Anatomi ve Patofizyoloji}

Kuadrilateral boşluk; önde subskapular kas, arkada teres minör kası, mediyalde triseps kasının uzun başı, lateralde ise humerus cerrahi boynun sardığı bir boşluktur. Omuz abduksiyon ve eksternal rotasyonda iken, posterior humeral sirkumfleks arter ve aksiller sinir sıkışması ile karakterizedir. Dinamik kompresyon yanı sıra, proksimal humerus ile skapula kırıklarında 


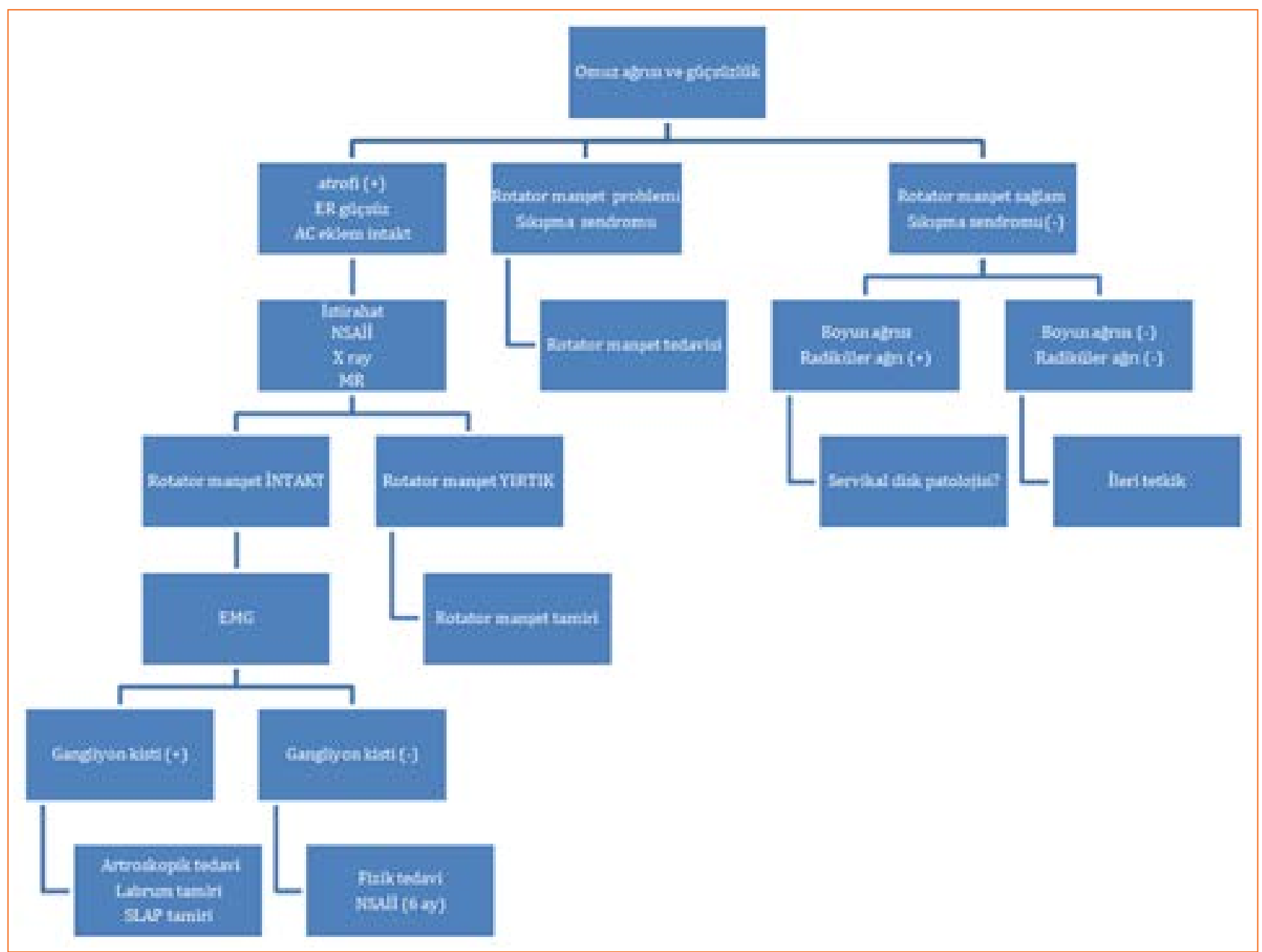

Şekil 1. Supraskapular sinir sıkışmasında tedavi algoritması. ${ }^{[6]}$

ve eşlik eden hematom, posteroinferior paralabral kist varlığında, teres minör kas hipertrofisinde, fibröz banda sekonder de sıkışabilmektedir. Subakut veya kronik aksiller sinir denervasyonunda, teres minör ve deltoid kas ödem ve atrofisi izlenir. ${ }^{[17]}$

\section{Klinik}

Hastada, iyi lokalize edilemeyen lateral ve posterior omuz ağrısı görülür. Genellikle geceleri, baş üstü aktivitelerden sonra ve fırlatmanın geç fazında ağrı belirginleşir. Fizik muayenesinde, teres minor ve deltoid atrofisi belirgindir. Kuadrangüler aralıkta, direkt palpasyonda ağrısı mevcuttur. Kol abduksiyonda iken, dış rotasyon kuvvetsizliği ve dirence karşı ağrının artması tipiktir. Minimal aksiller sinir duyu kusuru tespit edilebilir. Tekrarlayıcı omuz abduksiyon / dış rotasyon zorlamalarında, posterior sirkumfleks humeral arter (PSHA), kuadrangüler aralıkta ve humerus boynunun etrafını döndüğü bölgelerde sıkışır. vKAS tablosuna neden olan bu mekanizma, PSHA anevrizmasına/trombozuna neden olur ve dijital iskemi tablosu gelişebilir. ${ }^{[18]}$

Konvansiyonel grafiler, eşlik eden kemik patolojilerin tanımlanmasında önemlidir. MR, daha çok rotator manşet patolojilerinin ortaya konulmasında önemlidir. KAS'ın MR incelemesinde, teres minor atrofisi ve yağlı dejenerasyonu, inferior paralabral kist ve kuadrangüler aralığa direkt basıya neden olan kitle görülebilir. MR'de, kuadrilateral boşluk en iyi oblik koronal görüntülerde, aksiller sinir trasesi ise en iyi şekilde, omuzun rutin oblik sagittal, koronal ve aksiyel görüntülerinde izlenir. Sinir etrafındaki normal yağ planı seçilmelidir ve yer kaplayan kitle lezyonu olmamalıdır. Tanıda yeri olan incelemeler, vKAS düşünülen olgularda arteriyogram ve nKAS olgularda elektromiyografidir. ${ }^{[19]}$ 


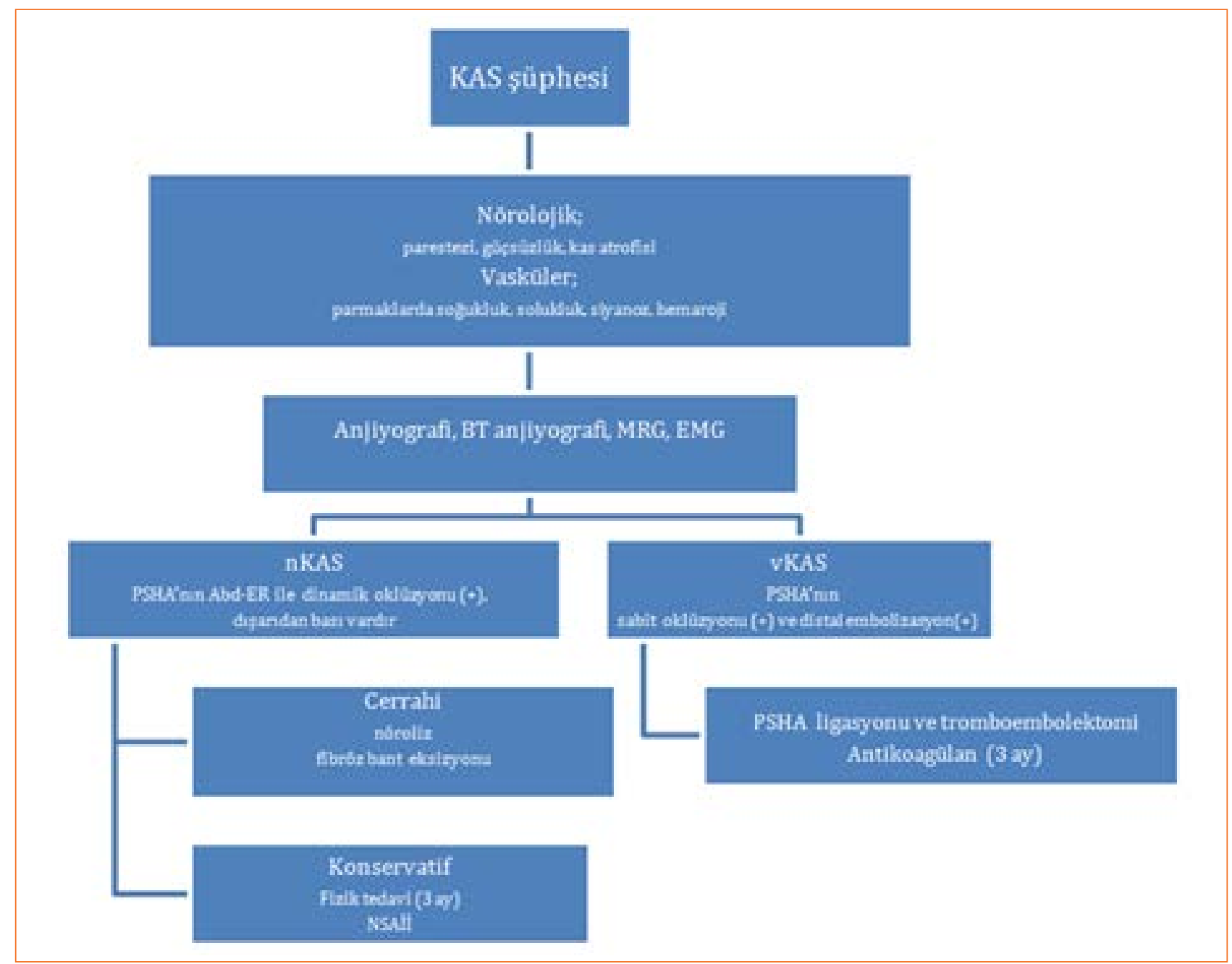

Şekil 2. KAS yaklaşım ve tedavi seçenekleri. ${ }^{[16]}$

\section{Tedavi}

Tedavisinde multi-disipliner yaklaşım önemlidir ve hastalar, ortopedik cerrahlar, kalp damar cerrahları ve nörologlar ile birlikte değerlendirilmelidir (Şekil 2).

\section{KAYNAKLAR}

1. Post M, Mayer J. Suprascapular nerve entrapment: Diagnosis and treatment. Clin Orthop Relat Res 1987;(223):126-36.

2. Edelson JG. Bony bridges and other variations of the suprascapular notch. J Bone Joint Surg Br 1994;77(3):505-6.

3. Cummins CA, Messer TM, Nuber GW. Suprascapular nerve entrapment. J Bone Joint Surg Am 2001;82(3):415-24.

4. Fabre T, Piton C, Leclouerec G, Gervais-Delion F, Durandeau A. Entrapment of the suprascapular nerve. J Bone Joint Surg Br 1999:81(3):414-9.

5. Witvrouw E, Cools A, Lysens R, Cambier D, Vanderstraeten G, Victor J, Sneyers C, Walravens M. Suprascapular neuropathy in volleyball players. Br J Sports Med 2000:34(3):174-80.
6. Romeo AA, Rotenberg DD, Bach BR Jr. Suprascapular neuropathy. J Am Acad Orthop Surg 1999:7(6):358-67.

7. Steiman I. Painless infraspinatus atrophy due to suprascapular nerve entrapment. Arch Phys Med Rehabil 1988;69(8):641-3.

8. Manifold SG, McCann PD. Cervical radiculitis and shoulder disorders. Clin Orthop Relat Res 1999;(368):105-13.

9. Fehrman DA, Orwin JF, Jennings RM. Suprascapular nerve entrapment by ganglion cysts: a report of six cases with arthroscopic findings and review of the literature. Arthroscopy 1995;11(6):727-34.

10. Martin SD, Warren RF, Martin TL, Kennedy K, O'Brien SJ, Wickiewicz TL. Suprascapular neuropathy. Results of non-operative treatment. J Bone Joint Surg Am 1997;79(8):1159-65.

11. Post M, Grinblat E. Suprascapular nerve entrapment: Diagnosis and results of treatment. J Shoulder Elbow Surg 1993;2(4):190-7. CrossRef

12. Aiello I, Serra G, Traina GC, Tugnoli V. Entrapment of the suprascapular nerve at the spinoglenoid notch. Ann Neurol 1982;12(3):314-6. 
13. Ludig T, Walter F, Chapuis D, Molé D, Roland J, Blum A. MR imaging evaluation of suprascapular nerve entrapment. Eur Radiol 2001;11(11):2161-9.

14. Huri G, Üzümcügil A, Biçer OS, Ozturk H, McFarland EG, Doral MN. An alternative endoscopic portal for suprascapular nerve approach: an anatomic study. Knee Surg Sports Traumatol Arthrosc 2015;23(5):1511-7. CrossRef

15. Cahill BR. Quadrilateral space syndrome. In: Omer GE Jr, Spinner M, editors. Management of Peripheral Nerve Problems. Philadelphia: WB Saunders; 1980. p.602-6.

16. Brown SAN, Doolittle DA, Bohanon CJ, Jayaraj A, Naidu SG, Huettl EA, Renfree KJ, Oderich GS, Bjarnason H, Gloviczki P, Wysokinski WE, McPhail IR. Quadrilateral space syndrome: the Mayo Clinic experience with a new classification system and case series. Mayo Clin Proc 2015;90(3):382-94. CrossRef
17. Vlychou M, Spanomichos G, Chatziioannou A, Georganas M, Zavras GM. Embolisation of a traumatic aneurysm of the posterior circumflex humeral artery in a volleyball player. $\mathrm{Br} \mathrm{J}$ Sports Med 2001;35(2):136-7.

18. Dugas JR, Weiland AJ. Vascular pathology in the throwing athlete. Hand Clin 2000;16(3):477-85.

19. Chen H, Onishi K, Zhao X, Chang EY. Neuromuscular ultrasound application to the electrodiagnostic evaluation of quadrilateral space syndrome. PM R 2014;6(9):845-8. CrossRef 